\title{
Groin pain
}

Farouk Dako ${ }^{1} \cdot$ Sayed Ali ${ }^{1}$

Published online: 29 November 2016

(C) ISS 2016

\section{Presentation}

Eighty-four year old female with history of knee osteoarthritis presents with new onset groin pain. Pelvis and femur radiographs show a lesion in the proximal right femur (Figs. 1, 2 and 3)

\section{Compliance with ethical standards}

Conflict of interest The authors declare that they have no conflict of interest

The diagnosis can be found at doi: 10.1007/s00256-016-2546-9

Farouk Dako

fdako123@gmail.com

1 Department of Radiology, Temple University Hospital, 3401 North Broad Street., Philadelphia, PA 19140, USA 

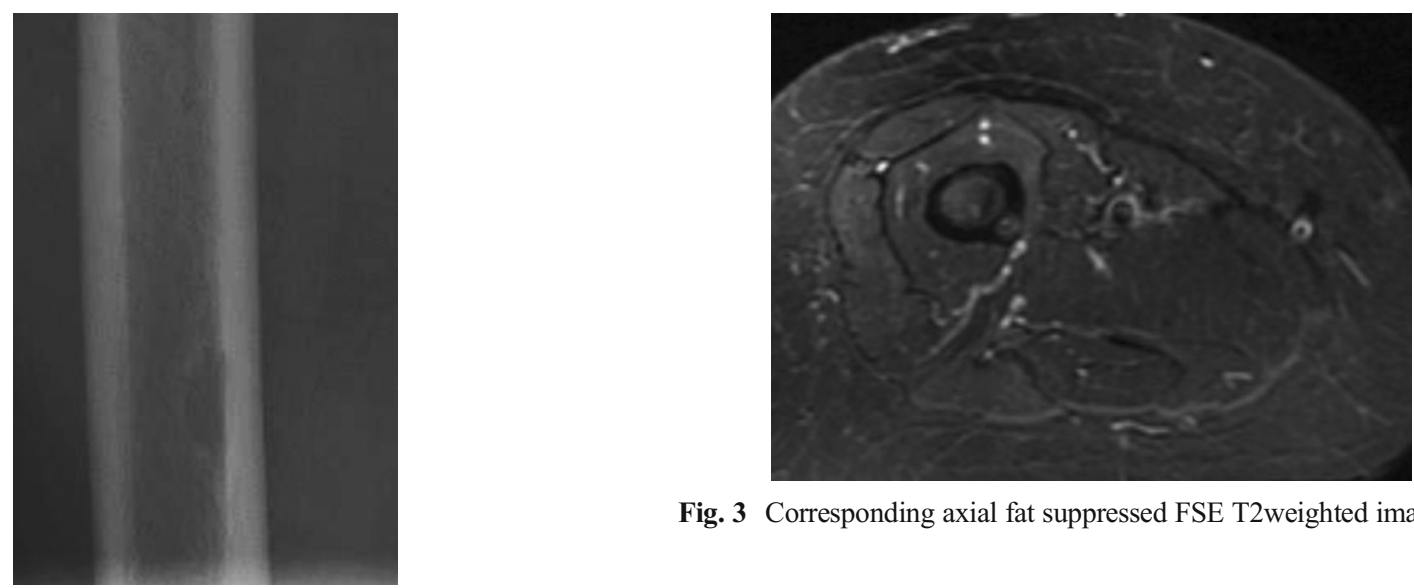

Fig. 3 Corresponding axial fat suppressed FSE T2weighted image

Fig. 1 Coned AP radiograph of the proximal femur

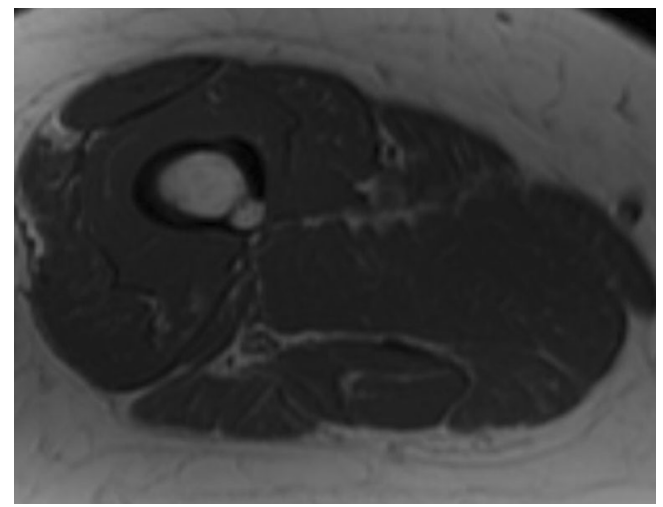

Fig. 2 Corresponding axial T1 weighted image of the proximal femur 